\title{
PSYCHOLOGICAL AND SOCIOLOGICAL APPROACHES TO STUDY RISK PERCEPTION
}

\author{
Ortwin Renn \\ Nuclear Research Centre, Programme Group: Technology and Society, Post Box 1913, \\ D-5170 Jülich, Federal Republic of Germany \\ Elisabeth Swaton \\ Joint IAEA.IIASA Risk Assessment Group, International Atomic Energy Agency, Post Box 100. \\ A-1400 Vienna Austria
}

(Received 28 December 1983; Accepted 5 August 1984)

Technological progress and its impacts on humankind has caused an increasing awareness of risk, and objective, statistical estimations are often inadequate to alleviate the public's fright and fear. Research on risk perception using psychological and sociological approaches is trying to bridge this gap. As a first step, a distinction must be made between the technical definition of risk (probability $\times$ consequences) and the social definition, in which additional parameters (source, dimensions, timeframe, exposure) need to be included. The methodology of risk assessment, though objective by design, is limited in the interpretability of its results, if the calculation of consequences does not take public perceptions and social effects into account. The problems and advantages of risk assessment are discussed, and the key question for risk perception research are presented. Various techniques are available to study risk perception and attitudes towards risk; selection of a specific technique is determined by the objective of the research, namely sociological implications or psychological cognitions. Several empirical studies in both areas are presented and the results discussed.

\section{Introduction}

The problems of nuclear energy, of new communication media, and of genetic engineering or chemical interference in the food chain have led to an increasing public concern on the issue of risk taking and risk acceptance. Mankind always experienced risks in life; the use of technical instruments has alleviated the pressure of natural selection and the dangers of natural hazards. Despite the main function of modern technologies to make life safer-even in the sense that social wealth leads to more protection for each member of society (Wildavski, 1980)-people became aware of the fact that the tools which liberated them from natural constraints posed new risks on their lives.

In this respect, the rank and meaning of the concepts of risk have undergone a significant change. Within the social context the term risk has a functional meaning for one's own behaviour only if the future is perceived as something that can be mastered or at least influenced by mankind. Natural disasters, war, famine, and diseases will remain inevitable events as long as mankind does recognize the possibility of intervening with foresight. However, the more that humanity has been able to produce situations and structures in the artificial biotope for the purpose of restricting or gaining control over potential damage, the more important it became to deal with the consequences of these actions. Thus, mankind arrived at the paradoxical situation in which the awareness of risks and the realization that we live in a dangerous world grew as the objective risks of life decreased-in this context, the probability of suffering damage or health detriments as a result of natural or manrisk sources (Renn, 1983).

However, with the taming of natural forces for productive purposes and the growth of economic consumption of goods, it was possible use technological progress to achieve a net profit in terms of safety, but only because costly safety devices and behavioral adaption largely prevent the potential catastrophe from happening. It is, therefore, a feature of modern technology that the extent of potential damage increases while the prob- 
ability of occurrence of a disaster is small. It does not matter whether the topic is dams, aircraft transportation, nuclear energy, or certain chemical plants; they all have in common that accidents occur rarely but involve high losses when they do occur. Thus, the centralization of large-scale technology has, as a result of comprehensive safety measures and tighter controls, reduced the degree of the individual risk (in this case, the probability of being killed or suffering health damage involving any technology), but has simultaneously increased the possibility of disasters.

A second effect is linked with the concentration of technical installations. In order to prevent the most improbable of all cases, i.e., the maximum credible accident, man must adapt his behavior to technology. This feature is not particular to modern technology. During the course of time, mankind has not only gained more freedom of action with the aid of technology, but in return technology has also forced the adoption of certain patterns of behavior. With the transition from the life of a nomad to that of a settled farmer, man achieved a higher degree of subsistence and improved physical protection; farming demanded more regular work, a fixed daily routine and normally also a longer working day.

The concept of risk entered mankind's awareness only when the future was perceived as being something that could, at least partially, be mastered or shaped; similarly, the possible restrictions were anticipated that may result from the consequences of technology already applied, after the future conditions of life were considered to be controllable. Fears that society would develop into a police state as a result of extended nuclear power production or of strict governmental conservation programs reflect the societal risk awareness which is directed more towards the social impacts of technology than to the health hazards involved (Conrad, 1981a; Renn, 1980).

\section{Risk in Societal Context}

The historical view on risk and society leads us to the focus of the contemporary risk debate. The term risk refers to a variety of concepts that vary according to the sources of risk, the dimensions of risk, the timeframe, and the spectator. Much of the misunderstanding and irritation on the side of the technical elite is due to the generalization of the mathematical definition of risk. The notion of a quasi-objective risk measure that allows a comparison between various risk sources and implies safety standards for acceptability disregards the social and cultural roots of the meaning of the term risk (Thompson, 1980; Douglas and Wildavsky, 1982).

The mathematical definition of risk (magnitude of losses $\times$ probability of occurrence) stems from a specific viewpoint common to engineers and natural scientists. It reflects their task and role in society. It should be made clear that risk - as a probabilistic measure of future adverse affects - cannot be regarded as a property or characteristic of an object. First, there must be a social definition of what is regarded as harmful or beneficial. Second, there must be an agreement of how to aggregate different adverse effects into one measure. Third, the assumption must be accepted that an accident which kills 365 persons on a single day during one year must be evaluated as equal to 365 accidents killing one person each day. Last, we must consider that secondary effects might occur as a result of a primary loss (for example, a suicide of a person who has lost his loved one in an accident). There is no doubt that on the basis of observations, epidemiological studies, experiments and mathematical or statistical modelling, one is able to determine probability functions over losses with respect to specific hazards (for example, cancer as a consequence of exposure to ionizing radiation), but the identification of "probabilities $\times$ magnitude of losses" with risk is more or less arbitrary.

Since our actions today influence the living conditions of tomorrow, the consequences of our behavior must be examined. To do this, the term risk must be used to calculate the likelihood of adverse effects by considering past experience with similar objects or with known elements of a complex new object (Covello et al., 1982; de Finetti, 1975; Björk and Hagberg, 1983). Many scientists agree that the meaning of risk is the probability or probability distribution that a particular adverse event or group of events will occur during a stated period of time (Renn, 1980; Royal Society, 1983). In this sense, risk assessment means the characterization of the potential adverse health effects of human exposures to environmental hazards (National Research Council, 1983). Usually the process of risk assessment is divided into four steps: hazard identification, dose-response assessment, exposure assessment, and risk characterization. Even if only results of epidemiological, clinical, experimental, or observational studies are used in characterizing the risk of a potential health hazard, specific assumptions must be made in formulating a summary judgement which relies on scientific conventions or subjective reasoning.

Some arguments shall be presented in support of this statement:

1. Estimation and identification of risk consequences has so far been possible only for direct damage to human health and to the environment, while other consequences (such as financial or social consequences) are difficult or even impossible to handle by numerical analysis. Those consequences are not included in the National Research Council risk assessment definition, which does not mean that they are irrelevant or negligible.

2. Any identification of consequences must, of necessity, consist of a selection from the unlimited number of possible error profiles. Even with systematic and highly 
differentiated model computations (such as fault tree analysis), it is impossible to predict all possible negative events and their consequences.

3. In addition to the limited nature of the scope of hazards identified by risk assessment procedures, it is necessary to limit the exposure paths in order to avoid endless speculation. For each negative event, secondand third-order consequences are conceivable which result as consequences of the next-higher order. Since the number of potential consequences rises exponentially with each additional order level, a convention is required with respect to the link in this chain, where the borderline of analysis is to be drawn.

4. The evaluation of orders of magnitude for risk consequences must be based on a substitutive relationship between those consequences. This applies not only to cost-effectiveness analysis, in which obtaining an optimum trade-off between cost and safety requires a certain flexibility, but also to any type of indirect consequences, such as the degree of security of facilities against sabotages versus the degree of acceptable limitations to the freedom of the staff working in that facility. Establishment of an optimal meeting point of several risk consequences can only be accomplished by either a subjective judgement or a convention between scientists, since a generally applicable yardstick for comparison of all risk consequences has not yet been established. Although the allocation of resources pertains to risk management, the identification of targets requires risk assessment techniques, where results strongly depend on the weighting of possible consequences.

5 . In the computation of probabilities, the problem arises of determining the statistical confidence intervals for the occurrence of accidents and possible consequences. This occurs because the statistical axioms of large numbers of observations, random distribution, independence of measured data, and constancy of environmental conditions are satisfied to an inadequate degree only (for instance, by a transfer of experience acquired on technical systems in a conventional facility to hypothetical computations of failures in a different technological context).

6. In addition, the spread of uncertainty is further increased by the infinite number of possible accident profiles; by the fact that certain entirely unusual chains of events cannot be foreseen; and by the limitation, required for technological reasons, to single events or two simultaneously occurring events (common mode failure).

7. In probability computations, failure factors such as human error can be calculated only with limited validity. In principle, there are three possibilities for the extrapolation of human failure in the manipulation of technological systems: game theory variant; probable operator error variant; or random operator error variant. All three methods are used in modern risk computation. The advantages and disadvantages of these three variants will not be discussed here. It should be ac- knowledged, however, that the choice of a variant to be used for estimating a risk remains a question of subjective estimation or scientific convention; different results are obtained, depending on the system used.

The sum total of this risk discussion is that risk assessment, by its very nature and under the present state of the art, cannot yield objective data in the sense of intersubjective validity. On the one hand, important areas always remain excluded (bounded rationality), and on the other hand it is unavoidable to use subjective judgment in various estimation processes (subjective rationality).

It is not intended, however, to create the impression that risk assessments are not meaningful because they cannot yield objective results. First, limited rationality statements are still better than pure intuition; second, the usefulness of scientific risk assessment does not consist of establishing an absolute risk figure describing the potential for hazards, but in developing a basis for a comparison of potential alternatives for achieving a certain benefit (risk-effectiveness method) (German Reactor Safety Commission, 1979).

But what are the main differences between risk assessments made by experts and risk perceptions by laypersons? The main difference lies in the way of using experience. Laypersons process personal experience with risk sources or collect available experiences from others (via interaction or media), whereas experts use the general experience of society ordered in a systematic and consistent form. Thus the two groups (experts and the general public) differ in their assessment with regard to the degree of abstraction, systematic classification, and reasoning.

Abstraction from personal experience and systematic approach - both characteristics of experts' perception can be regarded as an advantage for technological policymaking, but also as a shortcoming. The advantages are as follows: By finding a common denominator to evaluate different objects or events, experts are able to draw comparisons between totally different objects. They can evaluate different options with regard to expected losses and therefore recommend priorities in choosing optimal social solutions to risk-related problems. The systematic approach in risk assessment also guarantees "equal rights" for each assessed object. Everything is evaluated according to one common yardstick.

Both advantages can, of course, be interpreted as shortcomings, as Douglas and Wildavsky have noted (1982). First, the social and moral evaluation of specific hazards or hazard distributions is not taken into account (for example, cancer induced by a voluntary activity such as drinking or by an involuntary exposure caused by pollutants). Second, equity issues must be addressed, since all members of society are not equally exposed to various risks. It makes a difference whether one member of the society gains from the benefits and someone else 
must bear the risk, or if benefit and risk apply to the same person (Keeney, 1980). Third, society in general as well as specific groups in society associate beliefs with various risk sources and weight "expected values" differently depending on the person affected and on the nature of the hazard. (Douglas and Wildavsky provide many examples for cultural definitions of hazards and risk sources.)

Without doubt, scientific research always requires abstraction, and abstraction necessarily leads to omissions. Yet the question remains if expected losses forming the backbone of scientific risk assessment should be evaluated as the dominant factor for decisionmaking on risk issues. There might be more dimensions included in the concepts of risk, such as the offence of moral values, the loss of power and the challenge for freedom and equity. At the same time there might be other, even more appropriate, methodologies to summarize adverse effects into one formula. Within the scientific community of health risk researchers, an agreement has been reached to confine the term "risk assessment" only to the characterization of adverse health effects and to use the term "risk management" for the extension of the risk concept to social, economic, or political consequences of any technology or environmental hazard (National Research Council, 1983). It should be made clear that in other scientific communities the term risk assessment has a totally different meaning, for example in the economic or psychological literature (von Rosenstiel and Ewald, 1981; Lopes, 1983).

\section{Classification of Research Concepts}

In past years, risk perception research was focused on the contrast between expert judgment and intuitive perception (Fischhoff et al., 1981). Although most authors explicitly stated that his contrast was not meant as a confrontation between rational expert approach and irrational "common sense" reasoning (Jungermann et $a l ., 1982)$, the investigation of cognitive biases and errors can easily be misinterpreted as a search for distortions in risk perception. There is no doubt that experts on risk assessment are better informed about the general experience which society has collected over the years. At the same time, they are better prepared to use a consistent and mathematically sound technique to convert the information on past experience into the calculation of future behavior. But the technical definition of risk (expected losses) is implicitly based on the value assumption that the expected physical consequences are the ones that matter, and that taking the mean losses over time is the correct way to process statistical data of past experience. As we have pointed out before, these two assumptions are plausible and helpful for many purposes, but they should have no normative validity for all members of society.

The study of cognitive biases and heuristics is ap- propriate if risk assessors (regardless of whether they are experts or laypersons) violate their own rules of reasoning. Jungermann has discussed this issue in a recent paper on the two rationality camps in decision theory (1983). The overt violation of reasoning by laypersons can of course be interpreted as cognitive errors and biases. But it can also be seen as a rational behavior if both the reasoning process of the individual and the environment of the decisionmaking situation are taken into account.

Following this concept, we should conclude that we can only deal with risk perception as an attempt to master uncertainty by defining social goals (what should be considered) and applying a structure of reasoning which cannot claim a universal validity for all persons and risk objects. The "Key Questions" of risk perception can be summarized in the following way:

1. What are the social goals, values, or motives that drive persons or social groups to attribute special concerns to specific risk sources?

2. In what way do people process information about risk sources, and what kind of logical structure and reasoning do they follow in arriving at an overall judgement on the acceptability of a perceived risk?

3. What kind of motivational or cognitive biases are incorporated when people select information from the various sources which they have access to, and why do they apparently violate their own rules of reasoning?

Taking into account these three questions, we can develop a more integrated approach to the investigation of risk perception. For this purpose, we can divide the risk perception studies into four rough categories: classical decision analysis, psychological decision theory, social-psychological judgement and attitude theory, and sociological systems theory and policy analysis.

Classical decision analysis focuses on the rationality of the decisionmaking process under the assumption that we can make use of formal axioms to optimize our own judgement (Keeney, Raiffa, 1976). If we go a step further and demand that the optimization process be adapted to the individual metarational criteria of reasoning, this kind of research fits right into our Key Question 3 above.

Psychological decision theory (including social judgement theory) has put its emphasis on the individual process of common-sense reasoning incorporating the social desirability of perceived consequences and specific motivational factors in processing uncertainty (Hammond et al., 1978). Research in this field can be best classified under Key Question 2, because the purpose of this research is to head towards the individual process of understanding the representation and assimilation of perceived hazards and their probabilities, leading to the formation of an overall judgement.

Social-psychological research concentrates on the in- 
teraction between social environment (social values, norms, and roles) and personal judgement. Risk perception is being understood as a process of deriving attributes about specific objects from general social values and personal attitudes and linking these attributes to the perceived properties of the risk object or risk situation (Janis, Mann, 1977). This research lies on the borderline between Key Questions 1 and 2.

Finally, sociological research addresses the problem of group responses to risk concentrating on the influence of social values, institutional constraints, reference group judgements, communication, and power interchange (Frederichs et al., 1983; Nelkin, 1977b; Otway and von Winterfeldt, 1982). It is interesting to note that the sociological concepts of risk perception, in particular the studies on power and pressure groups, have some features in common with the concepts of the mathematical decision analysis - the other extreme of the scientific spectrum. Both concepts assume that individuals try to maximize their own utility (in sociological terms, their interest) and that objective measures can be identified to indicate if individuals or groups are better or worse off after the risk has been taken. (In decision theory, the expected utility is an objective measure of a person's gain or loss; in sociological theory, gain or loss of power is an objective yardstick to measure social influence). In our framework, sociological research deals primarily with Key Question 1.

Table 1 gives an impression of the scope of scientific research in the field of risk perception. It should be acknowledged that the systematic overview simplifies the complex situation of risk research and ignores much of the conceptual differences within each class. For a more detailed classification one should refer to the corre- sponding literature (see Covello, 1983; Otway, 1977; Royal Society, 1983).

\section{Reconstruction of Intuitive Risk Perception and Risk Acceptance}

For the purpose of reconstructing the mental path from the uptake of information to the final judgement, it is necessary to establish a terminology that can be used as a base for the introduction of the theoretical concepts and the description of the empirical studies. The following definitions are needed to understand the different approaches to study risk perception.

Risk Perception: Risk perception describes the process of mentally representing and assimilating the likelihood of adverse events that are connected with certain objects or activities and that might occur in the future (Renn, 1981).

Risk Acceptance: Risk acceptance reflects the results of balancing positive and negative consequences (utilities) and their probabilities by forming a general evaluative judgement of the riskiness of a certain object or activity (Renn, 1981).

Values: A value is a conception, explicit or implicit, distinctive of an individual or characteristic of a group, of the desirable which influences the selection from available modes, means, and ends of action (Kluckhorn, 1951).

Belief: A belief represents the cognitive images that a person possesses about a given object, i.e., it is a probability judgement whether an attribute is or is not associated with the perception of an object-and if it is, to what degree it is associated. The subjective feeling of

Table 1. Classification of risk perception studies.

\begin{tabular}{|c|c|c|c|}
\hline $\begin{array}{l}\text { Research } \\
\text { Scope }\end{array}$ & $\begin{array}{c}\text { Short } \\
\text { Description }\end{array}$ & $\begin{array}{l}\text { General } \\
\text { Assumption }\end{array}$ & $\begin{array}{l}\text { Application for } \\
\text { Risk Perception }\end{array}$ \\
\hline $\begin{array}{l}\text { Decision } \\
\text { Theory }\end{array}$ & $\begin{array}{l}\text { Matching the decision } \\
\text { process with normative } \\
\text { model of rational rea- } \\
\text { soning }\end{array}$ & $\begin{array}{l}\text { Maximizing utility of } \\
\text { individuals or groups }\end{array}$ & $\begin{array}{l}\text { Investigating the discrep- } \\
\text { ancies between norma- } \\
\text { tive risk assessment and } \\
\text { intuitive perception }\end{array}$ \\
\hline $\begin{array}{l}\text { Psychological } \\
\text { Decision } \\
\text { Theory }\end{array}$ & $\begin{array}{l}\text { Analysis of the individual } \\
\text { decision making process }\end{array}$ & $\begin{array}{l}\text { Existence of typical se- } \\
\text { quential structures to } \\
\text { make judgments under } \\
\text { uncertainty }\end{array}$ & $\begin{array}{l}\text { Investigating the cognitive } \\
\text { structure of the risk per- } \\
\text { ception process }\end{array}$ \\
\hline $\begin{array}{l}\text { Social- } \\
\text { Psycho- } \\
\text { logical } \\
\text { Theory }\end{array}$ & $\begin{array}{l}\text { Analysis of the social envi- } \\
\text { ronment as a determina- } \\
\text { tor for the decision } \\
\text { making process }\end{array}$ & $\begin{array}{l}\text { Dominance of social influ- } \\
\text { ence factors in perceiv- } \\
\text { ing and evaluating risks }\end{array}$ & $\begin{array}{l}\text { Investigating the influence } \\
\text { of value commitments, } \\
\text { social judgment and } \\
\text { communication pro- } \\
\text { cesses on the indi- } \\
\text { vidual decisionmaking } \\
\text { process }\end{array}$ \\
\hline $\begin{array}{l}\text { Sociological } \\
\text { Theory }\end{array}$ & $\begin{array}{l}\text { Effects and implications of } \\
\text { of social interrelations } \\
\text { between groups and in- } \\
\text { stitutions on collective } \\
\text { decisionmaking }\end{array}$ & $\begin{array}{l}\text { Risk taking as an element } \\
\text { of social exchange re- } \\
\text { garding resources and } \\
\text { power }\end{array}$ & $\begin{array}{l}\text { Investigating the interests } \\
\text { and social positions } \\
\text { which impose specific } \\
\text { risk perception proce- } \\
\text { dures }\end{array}$ \\
\hline
\end{tabular}


goodness or badness which is linked with each attribute refers to the effect a person might have and is called subjective evaluation (Fishbein and Ajzen, 1975).

Attitude: Attitude is a mental and neural state of readiness, organized through experience, exerting a directive or dynamic influence upon the individual's response to all objects and situations with which it is related (Allport, 1935).

In analogy to the theoretical concepts which have been briefly characterized above, three possible modes of risk perception are discussed in the relevant literature in order to combine these terms into a conceptual framework. In psychological decision analysis, human beings act on the basis of specific value clusters which influence the weighting of attributes connected with the perception of a given object. Specific psychological mechanisms of common-sense reasoning link the perceived properties of an object with the relevant attributes that have been weighted by individual values prior to the intuitive assessment process. Depending on what psychological model is used, the resulting judgement consists of a linear or nonlinear combination of preferences (weights) and perceived consequences. The overall judgement is furthermore influenced by common sense heuristics to cope with uncertainty (Tversky and Kahnemann, 1981). The public evaluates risk sources, not risks. But the intuitive mechanisms to master uncertainty and to arrive at a balanced judgement concerning the perceived hazards and benefits are largely determined by common rules of reasoning that can be identified and measured.

According to social psychological theory, the perceived properties of an object are transferred into a belief system in which not only object-related cognitions but also situation-related factors (such as the perceptions of the people who are in favor of the object) and symbolic attributes (such as national pride) are combined to form an overall image of the object. After each of these beliefs has been evaluated by the degree of emotional saliency (good-bad), an overall judgement can be derived (Otway, 1980).

In a more sociological view, the means of combining the beliefs into an overall judgement are of minor interest. The research focuses on the roots of the beliefforming process. If social groups are convinced that they will increase their power or gain more resources (money, status, or social influence) by taking a risk or supporting a risky object, they will collect or even create positive beliefs and neglect negative ones. The cognitions or attributes that are used to justify the decision must be interpreted as rationalization strategies to back up personal or group-related interests. General value commitments and perceptions of the society (overall belief system) are the intervening factors which on one hand determine the definition of gains and losses in the social game of acquiring influence, and on the other hand, structure the arguments to legitimize self-interest vis-à-vis all other groups in society (Hoos, 1980; Rammstedt, 1981; Conrad, 1981b; Perrow, 1984).

\section{The Empirical Transformation of the Conceptual Models}

By comparing the different approaches to studying risk perception we have concentrated our discussion so far on the theoretical background of each perspective. The methods of transposing the conceptual ideas into empirical research correspond, of course, with the specific tasks that are demanded by each perspective. Consequently different methodologies or techniques are applied for each concept.

In psychological research, psychometric scaling procedures and experimental designs are the predominant techniques used to gather data. Persons are usually confronted with a special task characterized by a forced choice situation involving risky alternatives. By varying the parameters of the task (for instance, changing the variance of a lottery, but keeping the expected values constant) the process of risk perception can be studied and special mechanisms can be revealed to cope with uncertainty (Ross, 1977; Tversky and Kahnemann, 1974; Royal Society, 1983).

Apart from cognitive psychological models, there have been a few attempts to use psychoanalytical methods to investigate risk perception (Tubiana, 1979; Wünschmann, 1984). Some theoretical studies on public opposition to nuclear power have tried to explain this resistance by using the tools of psychoanalysis. Such concepts as mythological fears, the transfer from food intake and discharge to the contamination of food and radioactive waste, and the displacement of fear to cope with nuclear armament have been dealt with (von Erichsen, 1962). Most recently, Wünschmann (1982) took up these studies and transferred Jung's archetype theory to the present dispute about solar and nuclear energy. The use of this psychological approach to study risk perception is a rather controversial issue among psychologists. Most researchers reject the psychoanalytical approach since it easily suggests the labelling of opposition to risk or risk objects as "deviant" or even "abnormal" behavior (Renn, 1984).

Social psychological research uses a wider scope of methods and techniques to study risk perception. The empirical tools range from experimental designs to public opinion polls. Most research is based on the following five procedures (Klineberg, 1954):

1. systematic observation of overt behavior in risky situations;

2. attitude measurement by means of questionnaire;

3. value elicitation through individual survey or group discussion;

4. revealed preferences through post-evaluation of historical social data; 
5. cultural analysis through content analysis or crosscultural survey methods.

The most popular method in social psychological research is measuring attitudes by means of personal interviews. This is because attitude research has a long tradition in social psychology. Moreover, simple but effective operational techniques are available. Also, attitude theory seems to be most appropriate to fulfill the main function of social psychological research, i.e., investigating social factors in individual decisionmaking (Rokeach, 1968).

Sociological studies on risk perception take risk as only one conceptual part within a broader issue, for instance technology dispute, diffusion of innovations, power play, social movements, or social change. Depending on the more general subject, empirical research is based primarily on survey methods or nonreactive techniques, such as observation, secondary analysis of statistical and demographic data, action research, and content analysis. Most empirical studies aim toward testing hypotheses on an aggregate level. Institutional responses on risk involving aspects such as social pressure and counterpressure in the attempts to influence official policymaking, or value commitments as the driving force of social movements, are forming a small collection of issues which have been discussed and investigated in sociological research (Mazur, 1975; Del Sesto, 1979; Nelkin, 1977a; Nowotny, 1976; Otway and von Winterfeldt, 1982; Kitschelt, 1980).

The results of direct measurements through surveys or observational methods must be incorporated into a prior hypothetical framework, which means that the interpretation of the data leaves much room for speculation. The broader the spectrum of phenomena to be studied, the easier it is to "find" evidence for any hypothesis to be empirically verified.

However, a narrower approach, such as that needed in psychometric studies, faces the danger of distorting the actual relationships between empirical phenomena by restricting the scope of research to predetermined parameters which might be only surface variables concealing the underlying causal structure. Thus, the need for studies on all three perspectives is even more justified in the light of the specific deficiencies that arise in pursuing each of these perspectives. Progress in understanding risk perception can be achieved only if more interdisciplinary work is introduced and communication between the scientists concerned is improved.

\section{Selected Results of Psychological Risk Perception Studies}

\section{Framework of the Jülich Perception Study}

The awareness of the general public regarding risk and technology has resulted in an avalanche of psychological and sociological studies on risk percep- tion. It would be beyond the limits of this study to give an overview of all relevant work in this field. A summary of those empirical studies may be found elsewhere in the literature (Otway, 1977; National Council on Radiation Protection and Measurements, 1979; Thomas, 1981; Slovic et al., 1980; Royal Society, 1983; Renn, 1981, 1984).

In this section the authors shall present some results from studies they have undertaken in the past four years. The psychologically oriented research was conducted by the program group "Technology and Society" of the Nuclear Research Centre Jülich (Federal Republic of Germany); the social psychological studies were conducted by the Joint Risk Assessment Group of the International Atomic Energy Agency and the International Institute for Applied Systems Analysis. The following sections shall describe the results of surveys and experiments in which the authors themselves were involved.

First, the studies covering the mechanisms of intuitive risk perception will be discussed. The empirical work was highly influenced by the pioneering studies of Slovic, Fischhoff, and Lichtenstein, who laid the basis for the initial methodology to investigate risk perception (Fischhoff et al., 1978; Slovic et al., 1981a). Those early studies have been supplemented by a variety of new research techniques, thus enlarging the original psychological concept.

If one attempts to summarize the significant factors in risk perception on the grounds of empirical studies performed to date, three levels of influence are to be mentioned:

1. perceived expected losses (estimates of average loss rates per unit time);

2. perceived disaster potential (estimates of the maximum conceivable accident);

3. qualitative risk characteristics (circumstances accompanying the risk situation such as voluntariness or possibility of personal control).

Beyond these three cognitive influence factors that affect the process of intuitive risk perception (omitting the specific beliefs about the risk source), there are also features that relate to personality such as risk propensity or benefit orientation (motivational factors). These will be included as a separate category for analyzing determinants of risk perception.

\section{Expected Values and Catastrophe Potential}

In actuality and in scientific risk theory, the expected values of adverse effects resulting from damage to an installation or a malfunction of a technology are synonymous with the term risk. Risk sources are roughly judged according to how many losses per unit time are to be expected on the basis of experience or hypothetical calculations. 


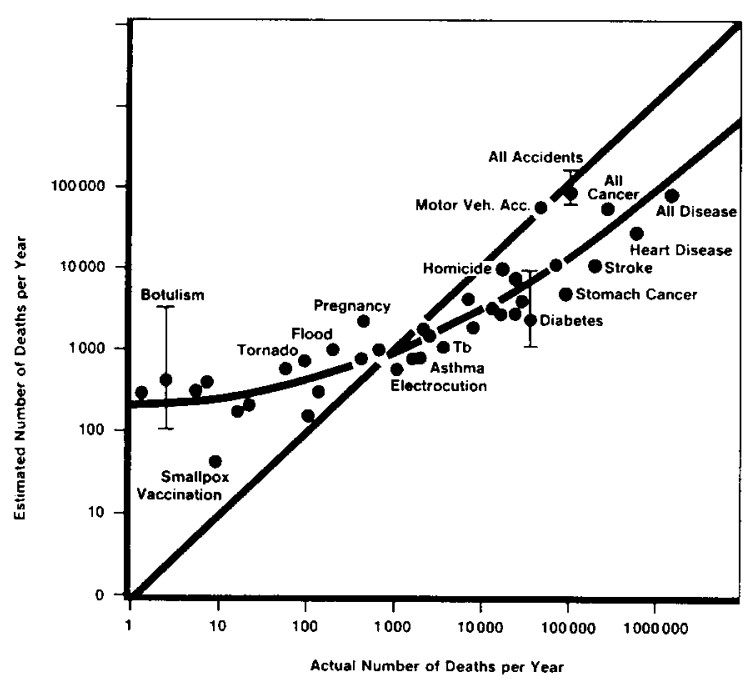

Fig. 1. The respondents' estimated number of losses for the various risk sources as compared with the statistically computed values (U.S. survey). Source: Lichtenstein et al., 78. (Reprinted with permission from Exper. Psychol.: Human Learning and Memory 4, 551-578, 1978, a publication of the Helen Dwight Reid Educational Foundation.)

The question if risks are intuitively rated according to expected losses can be answered with the aid of Figs. 1 and 2. A list of different risk sources were presented to an American (Lichtenstein et al., 1978) and a German sample (Renn, 1981). The respondents were asked to estimate the average fatalities for a normal year. The estimated values determined in this way are represented in the two graphs by the ordinates, and the real statistical figures are plotted on the abscissa.

It can be clearly seen from the two figures that the intuitive loss expectancy and the statistically expected values are relatively close together. The American interviewees underestimated risks with high loss rates and overestimated risks with low loss rates, i.e., the variation in values for the intuitive estimation of average losses is significantly less pronounced and is more closely approximated to the general mean. A similar trend can be determined in the German investigation; however, a slight overestimation of all loss expectancies without exception can be observed here.

If one relates the statistical or intuitively estimated values for expected losses to the intuitive rating of the risk level (further referred to as risk perception), the benefit level (benefit perception), or a risk-benefit ratio (risk-benefit perception), one obtains an astonishing result. Presumed loss rates per year and risk perception (also risk-benefit perception) are practically independent of each other, i.e., most people do not assess risk sources according to the presumed losses per year, rather they concentrate on other points of view (Renn and Peters, 1982). This insight is true not only of the German interviewees; American, English, French, and Australian studies confirm the low relation between the public's loss estimation and risk perception (Slovic et al., 1979; Glennon, 1980; Pages et al., 1982).

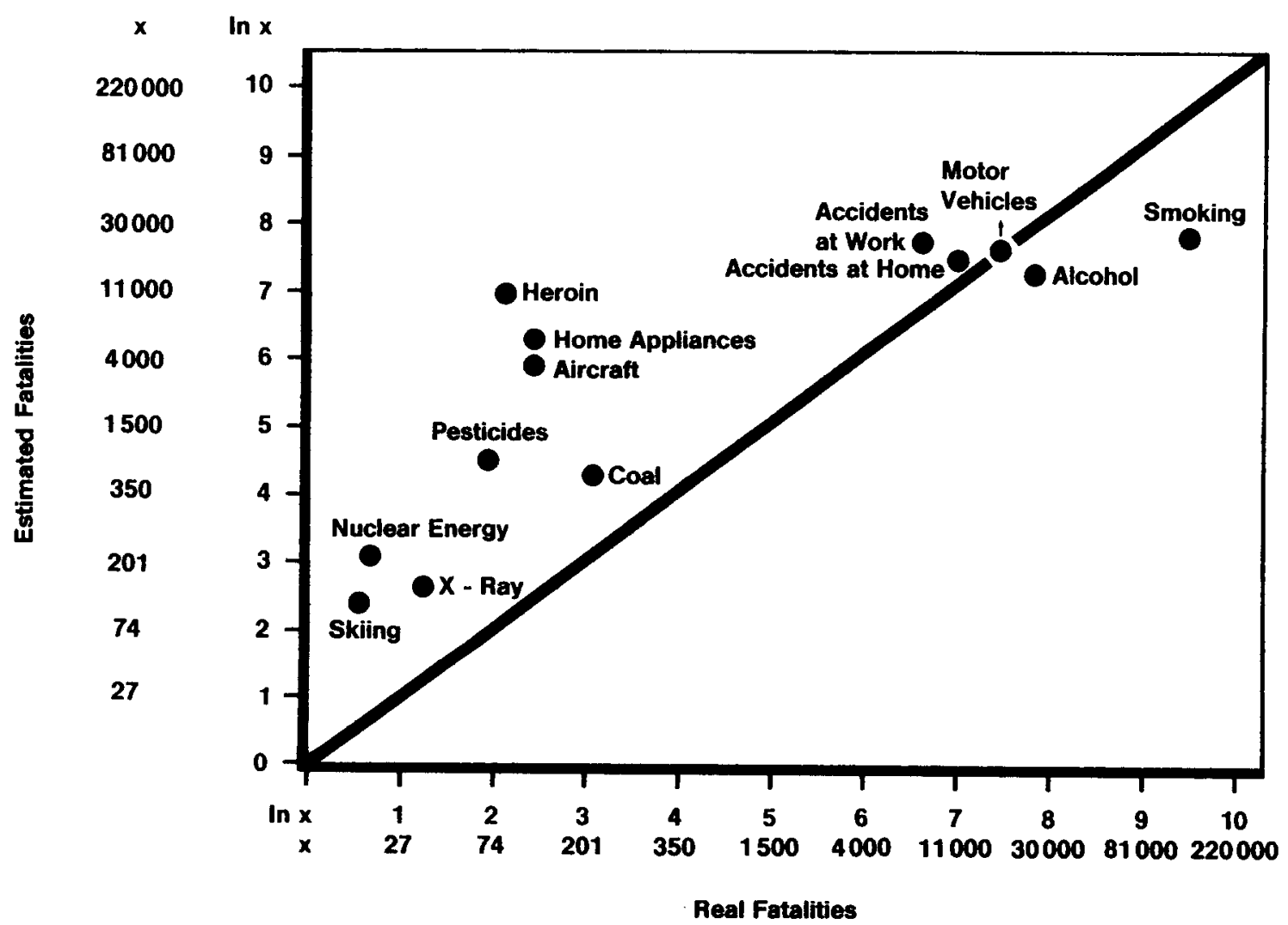

Fig. 2. The respondents estimated number of losses for the various risk sources as compared with the statistically computed values (German survey). Source: Renn, 81. 
Thus, most people are more or less aware of the expected values of well-known risks; however, the expected values are merely one factor among many in the perception of these risks and, as correlation analyses show, a factor with only slight explanatory value.

Since the expected values of risks are defined as the sum of adverse consequences multiplied by the probability of their occurrence, a suprafactorial relationship between the two factors could, of course, be present in the public perception of risk. In this case, the difference between statistical and intuitive evaluation would not be based on the use of expected values, but rather on their combination. Therefore, in some decision analysis studies an exponent is added to the risk equation which takes into consideration the subjective utility attribute (or risk evaluation) of different orders of magnitude (Okrent and Whipple, 1977). In particular, the hypothesis has been put forward that the hazard potential in the case of risk (that is to say the extent of the maximum conceivable accident) has a significant influence on the perceived risk level regardless of how low the probabilities are. Whereas Slovic et al. were only able to prove this type of influence in the case of nuclear energy (1981b), von Winterfeldt et al. (1981) report a partition of risk sources into individual activities, which are assessed with better reference to the average expected value, and technological sources, which are principally evaluated according to the most severe accident considered possible.

In contrast, our own investigations suggest a different conclusion: most people are not able to give reasonable judgements if asked to evaluate potentials of catastrophes. Since their experience with catastrophes is rather limited, their judgement about uncertain events can only be based on media coverage or general cognitive heuristics. If a risk source has been extensively covered by the media, people tend to overestimate the potential fatalities. In the case that media or intuitive fantasy does not provide easily accessible images of disaster, people heuristically perceive the risks of disaster stemming from various risk sources as being of the same order of magnitude. Orientation towards the mean value is psychologically a typical response pattern when confronted with a stimulus that evokes high uncertainty. In addition, correlation analyses between perceived catastrophe potentials and risk perception indicated that, with the exception of a few risk sources, catastrophe potentials do not exercise a dominant influence on risk perception.

\section{Qualitative Risk Features}

The related circumstances - the way in which people are exposed to a certain risk-are considered in the literature to be an essential explanatory variable class for the perception of risks. What is meant by this?

The authors conducted a small experiment with 36 respondents chosen at random. The subjects were asked by the organizer of the test to take part in a trial of phar- maceutical products, which was supposed to be testing three different capsule coatings with respect to possible unpleasant side effects. According to the organizer of the test, the coating of the first capsule contained radioactive material, the second bacterial material, and the third heavy metal, with the effect that all three dissolved in the stomach more quickly than conventional capsules. The respondents were assured that none of the three capsules presented any risk to health. (In reality, the capsules were three identical commercially available vitamin preparations.) One group was offered a free choice from the three possibilities; to each member of the group one of the capsules was given by the organizer of the experiment. After taking the capsule the test subjects had to fill in a questionnaire, on which they were asked to indicate possible ill effects (stomach pains, nausea, etc.). The result of this experiment is depicted in Fig. 3. Although all the test subjects had swallowed an identical capsule, the members of group 1, who had not been allowed to choose, said that they felt unwell on the average twice as often as those who had been able to choose a capsule. This result was completely independent of which capsule coating they had chosen or were directed to take. An interesting marginal note is the fact that the allegedly radioactive capsule caused ill effects in both groups most frequently.

That voluntariness represents a significant parameter in risk perception has long been an important component of psychological risk and decision theory. Starr (1969) has underlined the significance of this relation in quite a different way. A comparison of statistical loss rates caused by various risk sources provided the insight that socially accepted risks, which are entered into voluntarily, show a thousand times higher loss rate than risks which can be regarded as forcibly imposed.

Voluntariness is only one of many risk features that in the meantime have been recognized as variables of influence in risk evaluation. Investigations performed by the Decision Research Group (Eugene, OR) revealed three factors as particularly relevant: the common dread of an accident, its unfamiliarity (unknown risk), and the exclusiveness of the risk (societal versus personal risk taking) (Slovic and Fischhoff, 1984).

We also tested the significance of the qualitative variables analogous to the U.S. investigations. In addition to risk-related features, we included benefit-related attributes, for example "profit personally from it" or "it benefits everybody to the same extent." In order to estimate the joint influence of these qualitative features on the perception of risk and benefit, multiple correlation procedures (regression techniques) were applied, by means of which the joint influence of the independent variables on the phenomenon to be explained (in this case risk-benefit perception) can be measured.

Figure 4 shows the relevance of the qualitative features for the evaluation of the risk in question for nine risk sources. The correlation coefficients, which indicate the intensity of the relationship, constitute the $y$ 


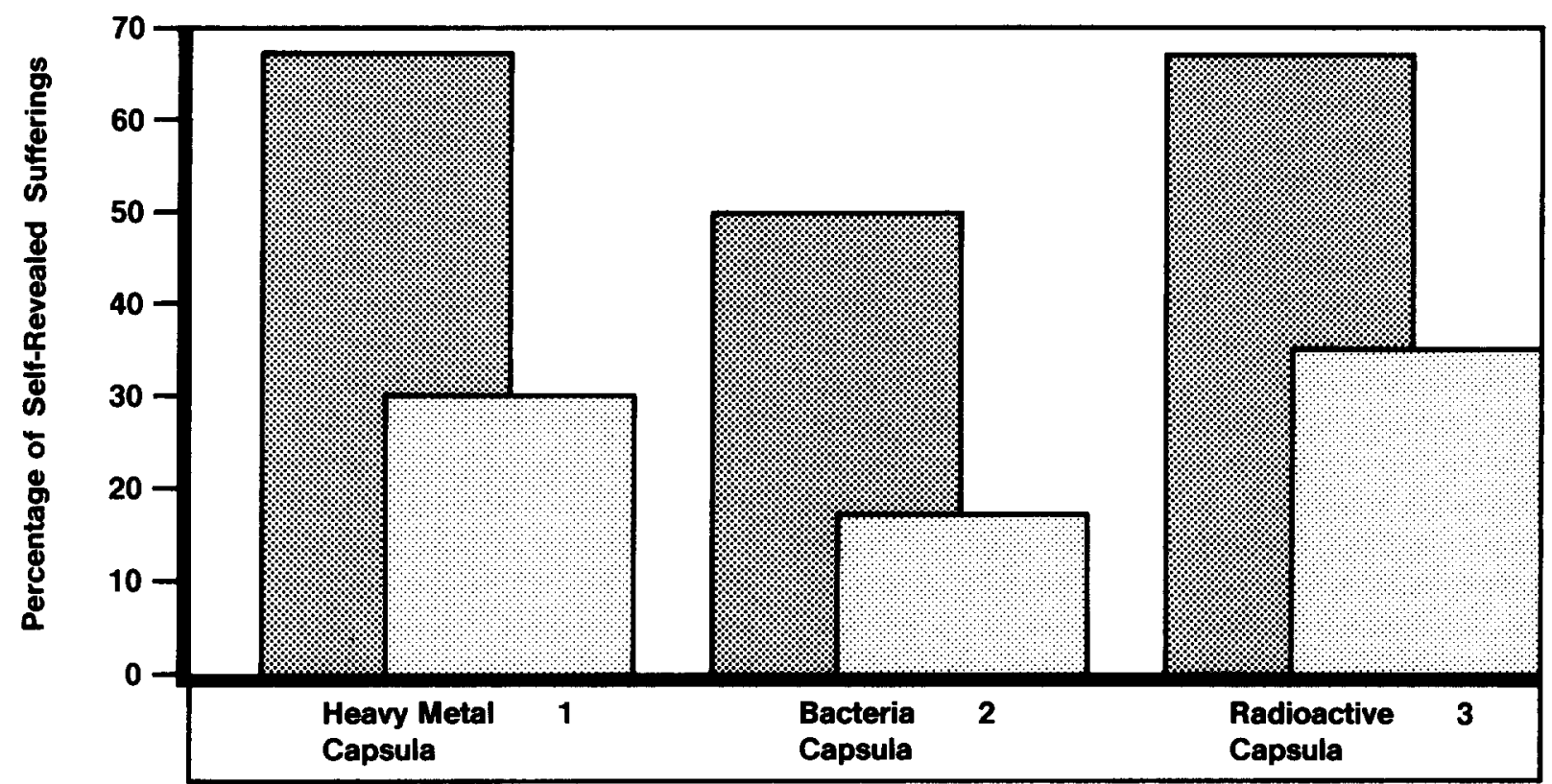

Group II (Involuntary Risk-Taking)

Variance of Experimental Design

Group I (Voluntary Risk-Taking)

Fig. 3. The results of the capsule experiment: Two test groups received identical vitamin capsules with allegedly different coatings consisting of heavy metal, bacteria or radioactive substances. The members of group 1 could take any capsule of their choice; the members of the second group were forced by the experimenter to swallow one of the three allegedly different capsules. Subsequent to the experiment, the subjects were requested to state their subjective complaint such as stomach aches. In this connection it became evident that the voluntary risk-taking resulted in a significantly lower number of complaints. Source: Renn, 81 .

axis, while the $x$ axis is defined by the boxes with the individual feature classes for the nine different risk sources.

If one first considers the primary factors, that is to say those aspects which exert the greatest influence on risk-benefit perception, it becomes apparent that benefitrelated points of view predominate. People first evaluate risk sources according to the possible benefits and the related effects of their application, for example whether they themselves can profit from them, whether they are of benefit to everyone or only to a minority, or whether they are convinced that other alternatives are available which provide the same benefit with less risk. In the case of nuclear energy, pesticides, and electrical appliances, the emphasis is on risk characteristics. Whereas the voluntariness of utilization brings about a positive weighting of the concomitant risk in the case of electrical appliances, the predominance of the factor "catastrophic consequences possible" in the case of nuclear energy and "possibilities of long-term damage" in the case of pesticides has a negative effect on risk perception. In spite of these findings, a dominant role for qualitative features in intuitive risk evaluation cannot be deduced from the correlation coefficients, although their influence is quite clear. The proportion of declared variance for the independent variable "risk evaluation" is under $25 \%$ in the case of almost all individual risk sources (Renn, 1982).

\section{Personality Features and Social Attitudes}

As a separate influence level, we should mention certain individual characteristics and features that can shape the cognitive structures of risk perception. Here we are not concerned with the social or psychological patterns of the attitude field, but rather with people's risk-related thought and deduction processes. Utility theory has always differentiated between people who are risk-averse, indifferent to risk, or risk-prone. Proof of the influence of personal orientation on one's own behavior has been repeatedly furnished for "gambling situations," which are particularly typical of this discipline (Schäfer, 1978; Tversky and Kahnemann, 1981).

In our studies it became apparent in the question of personal risk propensity that a positive risk-benefit estimation of technical and industrial sources requires positive risk propensity, but that this is not necessary for stimulants such as smoking or drinking. Stimulants, which can be individualized, are only classified as less acceptable if there is a consciously negative relationship to risk; technical or industrial risks, however, already encounter acceptance difficulties if there is no favorable attitude towards accepting risks.

General sociopolitical attitudes are then related to risk perception if conflicts about the risk source have already led to polarized and politicized points of view in society. An example of this is given in Fig. 5, which 


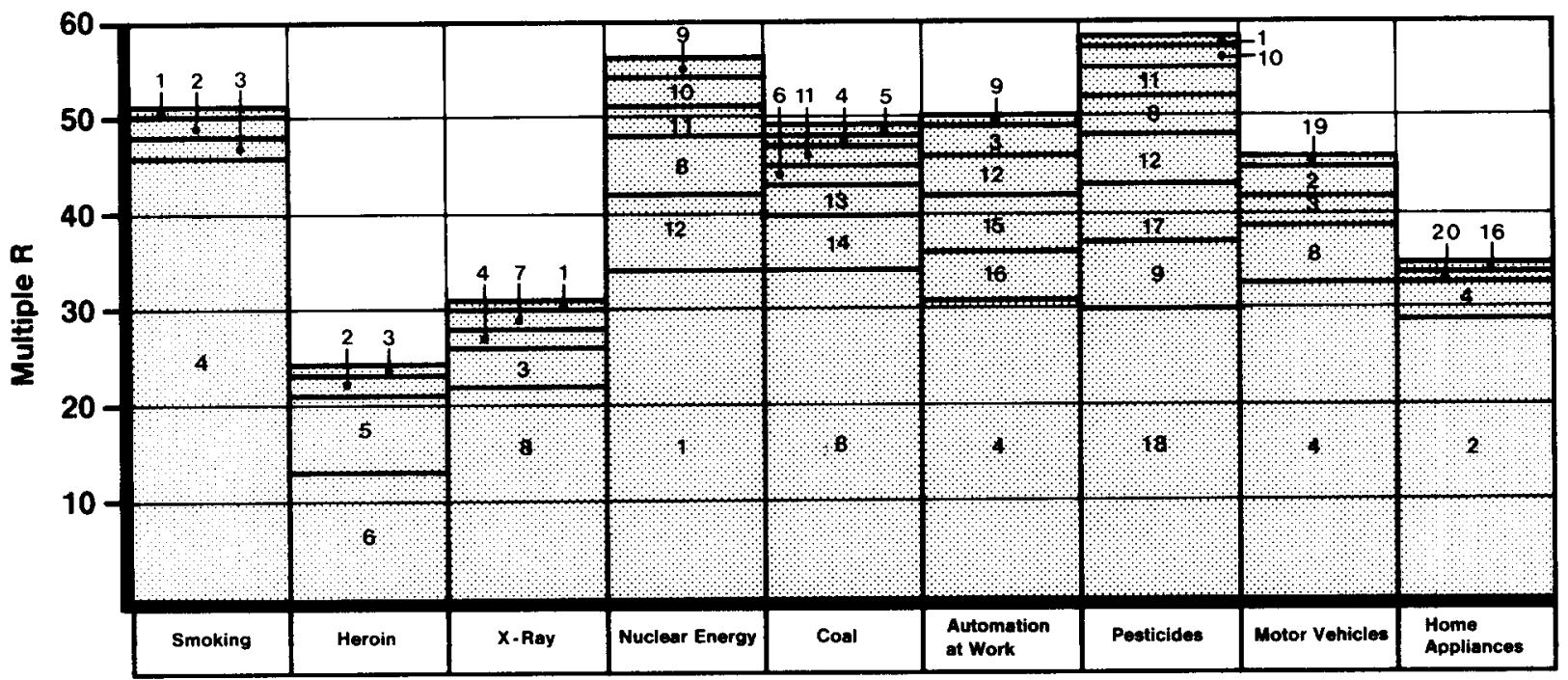

Risk-Object

1 Severe Consequences
2 Voluntary
Risk Taking
3 Personal Control
4 Personal Benefit/Risk
5 Hazards Well-Known
6 Available Alternatives
with Equal Benefit
7 Everyday Risk

\section{Equal Benefit Distribution \\ 9 Safety under \\ Public Control \\ 10 Inperceptible Risk \\ 11 No Personal Control \\ 12 Extraordinary Hazard \\ 13 Involuntary Risk \\ 14 Immediate Consequences}

\author{
15 Unknown Hazard \\ 16 Minor Consequences \\ 17 No Available Alternatives \\ with Equal Benefit \\ 18 Delayed (Long- \\ Term) Consequences \\ 19 Safety under \\ Public Control \\ 20 Technically Advanced
}

Fig. 4. The relation between qualitative risk and benefit characteristics and the intuitive rating of the risk-benefit ratio of the various risk sources (multiple correlation coefficient). Source: Renn, Peters, 81.

shows the relationships between the intuitive riskbenefit ratio of nuclear energy and five sociopolitical attitudes.

The results of the Jülich studies on risk perception give a clear indication of the way in which people perceive risk sources. Most people have generally reliable beliefs about the average loss rates from various risks, which-unlike scientists and actuaries-they do not regard as a sole criterion for risk assessment. The accompanying circumstances of the hazardous situation and the expected consequences for general social, economic, and future-oriented interests are of central significance for them. In addition, personal attitudes towards hazardous circumstances and general value beliefs according to the degree of political polarization which vary from individual to individual - play a major role.

\section{Selected Results of Social Psychological Studies}

\section{Framework of the IAEA Attitude Study}

The influence of social attitudes upon the risk perception process is related to the social psychological studies which we have undertaken in various countries. All these studies are based on the attitude concept developed by Fishbein (1963). They were organized and managed by the Joint Risk Assessment Group of the International Atomic Energy Agency (IAEA) and the International Institute for Applied Systems Analysis (IIASA). As an illustration of the method and the results, we chose to study attitudes towards nuclear energy, comparing student samples of West Germany, Japan, and the Philippines (Swaton and Renn, 1984).

Since attitude theory requires certain objects or persons to be the target of attitude formation, we can only investigate attitudes towards specific risk sources. Thus, all attitude research is based on concrete objects from which general conclusions about risk-related beliefs can be derived.

\section{Method and Procedure}

According to Fishbein and Ajzen (1975) the terms to be used in their technique are combined in the following ways:

$$
A_{\mathrm{o}}=\sum_{i=1}^{n}=b_{i} \times e_{i}
$$



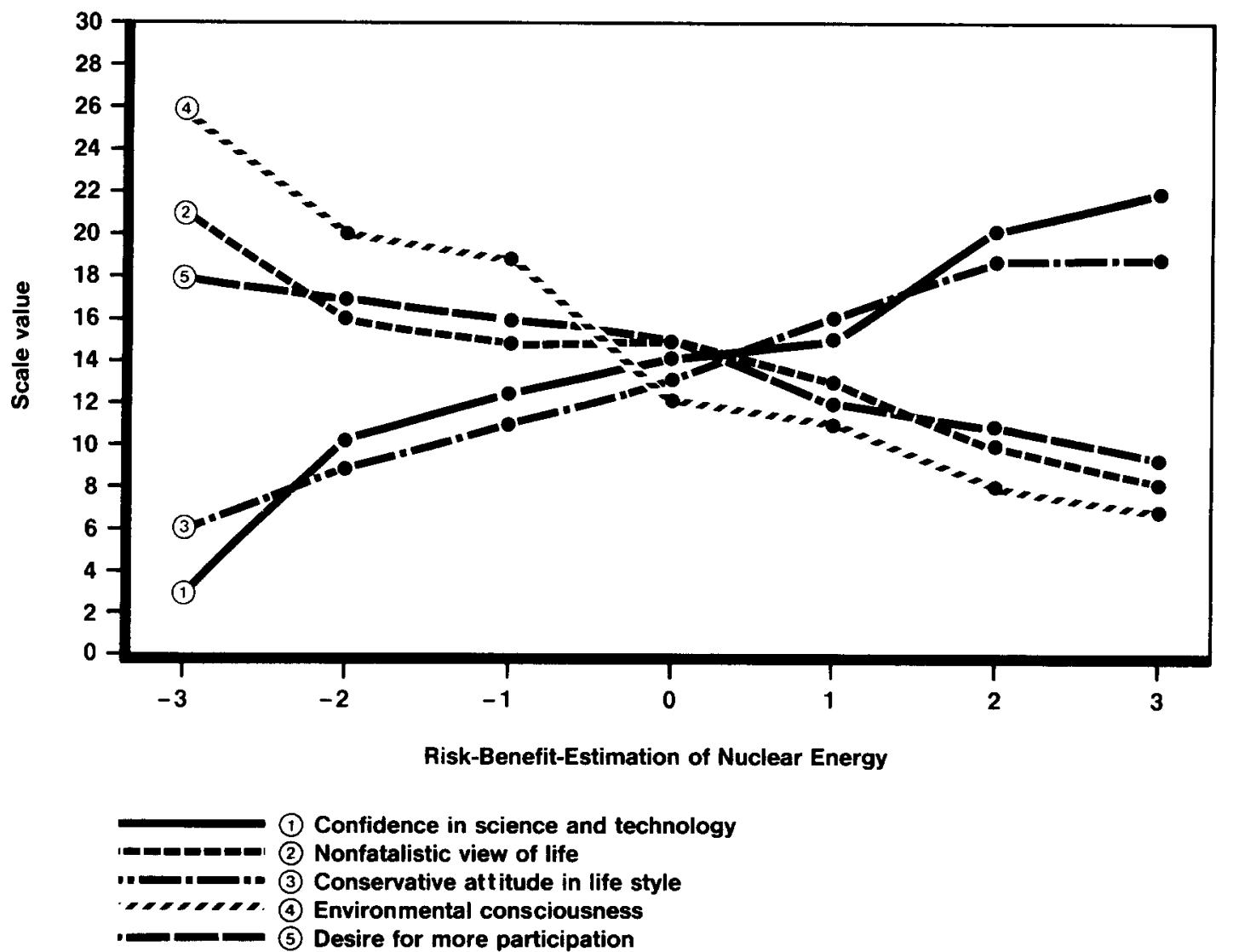

Fig. 5. Five socio-political attitudes (Likert-scales) as a function of risk-benefit estimation with regard to nuclear energy. Source: Renn, Peters, 81 .

where $A_{o}$ is the attitude toward the given object; $b_{i}$ is the belief about the object, expressed as subjective probability that the object is related to attribute $i$ (attribute is a description of dimension or concern which links the perceived characteristics of an object with the value orientation of each individual; $e_{i}$ is the evaluation of attribute $i$; and $n$ is the number of beliefs (units of information) a person holds about the attitude object in question.

The design of the questionnaire pertaining to the Fishbein technique requires a careful selection of the attributes. The questionnaire used in the study was developed in the following way. A first version was compiled after extensive screening of mass media and relevant literature to get a feeling for issues of concern; then approximately 100 people in Vienna were interviewed and asked what came to their mind when they thought of "nuclear power." These issues, augmented by those found in the literature, provided the basis for the pilot questionnaire, which was then applied in Austria to a stratified sample (Thomas et al. 1980). The next step implied some modifications of the original version of the questionnaire, so that it would be applicable in other countries as well; this meant the inclusion of issues that had been repeatedly raised in the participating countries.

All three samples for the international study are groups of students from technical universities: the West
German students are enrolled in Aachen and Cologne ( $n=150)$, the Philippine students in Manila $(n=174)$. The data for the Japanese students have been obtained from two cities: Tokyo $(n=36)$ and Osaka $(n=84)$.

One difficulty with cross-national surveys is the difficulty of finding appropriate samples which allow comparisons between countries. The use of randomly chosen groups out of the general public is inappropriate, if the basic educational level and the knowledge concerning the issue of the questionnaire are not equally dispersed between the different national samples. Since attitudes on energy systems are partly determined by the level of knowledge, we decided to confine our samples to students of technical and natural sciences. We assumed that students around the world have at least a basic understanding of the functions and purposes of different energy systems.

\section{Statistical procedures}

Apart from the normal statistical procedures, such as frequency distribution analysis and correlations, we applied four more sophisticated methods in order to reduce the amount of variables to a smaller number of salient elements. The techniques involved are: (1) semantic differential, (2) factor analysis, (3) multiple regression, and (4) discriminant analysis.

Semantic differential is a method frequently used in psychology to measure the emotional standpoint of a re- 
spondent with respect to a person or an object. A semantic differential consists of pairs of adjectives, such as right-wrong or dirty-clean. The respondents are asked to evaluate the given object between the two extremes for each pair of adjectives. We used the semantic differential method to create a simple scale value for the overall evaluation of nuclear energy.

Factor analysis is a method to determine the underlying cognitive structure in a given set of attributes by comparing the similarities of variance distributions resulting in a combination of items with high intercorrelations. The main purpose of a factor analysis is to derive dimensions that are inherent in a larger set of items.

Multiple regression indicates the strength of a relationship between one dependent variable and a set of independent variables, whereby the intercorrelating items of the independent variable set are excluded from the analysis. This procedure explains for each independent variable (e.g., attribute) the additional amount of the declared variance of the dependent variable (e.g., semantic differential as direct measurement).

Discriminant analysis provides a viable yardstick for evaluating the relative distance between various subgroups of a given sample. As with multiple regression, an entire set of possible discriminative variables can be investigated, and the result of the analysis reflects the significance of items as determinators of for group differences.

\section{Distribution of Positions and Analysis of the Belief Structure}

First, we looked at the direct measure introduced in the questionnaire via a simple self-rating of one's own attribute, revealing the position of the respondent with regard to nuclear energy (Pro/Con Scale from -3 to +3 ).

Figure 6 shows the respondent frequencies given in percentages for each response category in each sample. The figure shows that the Japanese students were predominantly in favor of the use of nuclear energy (categories 2 and 3 account for $68 \%$ of the sample). The Philippine student sample includes two groups-one strongly opposed (category -3 accounts for $25 \%$ ) and one slightly in favor (category 1 represents $20 \%$ ). The German students are also composed of two groups, with $45 \%$ of the sample being in favor of the use of nuclear power (categories 2 and 3 ) and a smaller group of $25 \%$ (categories -3 and -2 ) being against.

In a second step, we investigated the structure of the belief system. Application of factor analysis to the belief scores is expected to reveal the cognitive structure of the respondents concerning their perception of the issues pertaining to the use of nuclear energy.

Philippines: The results of factor analysis of the belief scores on nuclear energy are given in Table 2 . Items with high intercorrelations cluster around two aspects, the risk considerations and the benefits, where the latter are distinguished by having an effect on the national level or a rather personal level. The analysis revealed three factors:

1. Factor I has been labelled "Negative Impacts of Large-Scale Technology." The issues involved include the lack of active control over the hazard and the involuntary exposure to it, the concern about large accidents, and the health hazards created either directly or indirectly through burdening the environment.

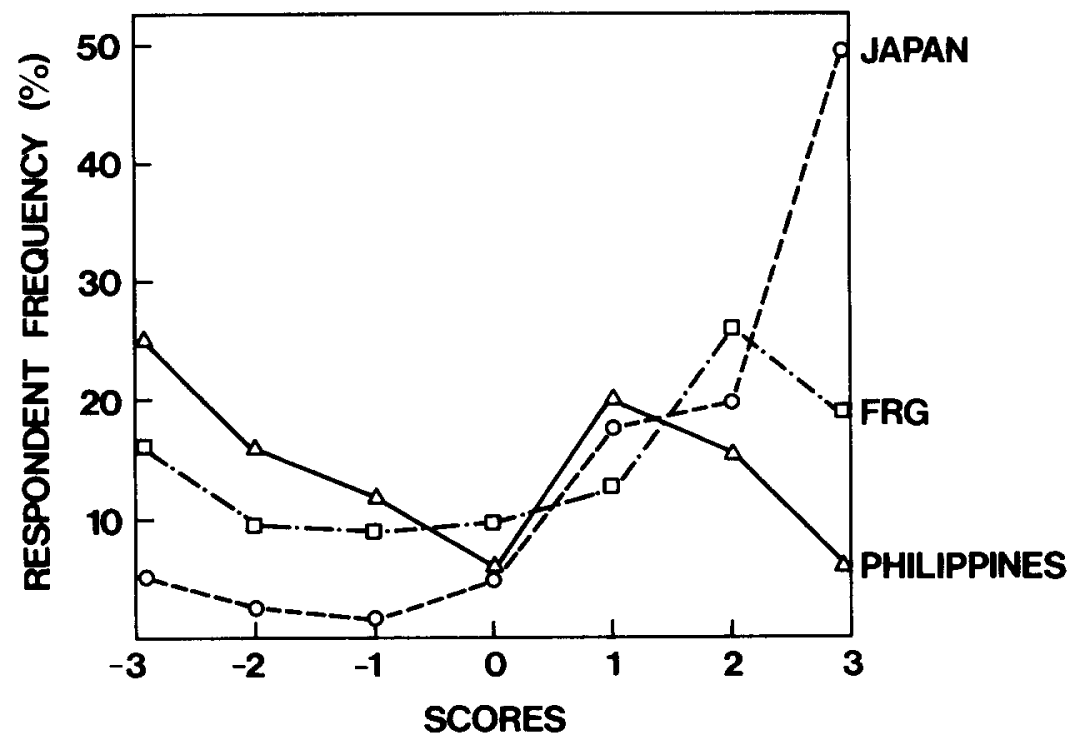

PRO/CON Scale Frequencies

Fig. 6. A comparison of the distribution of attitudinal commitments ( -3 totally against nuclear power, +3 totally in favour of nuclear power) between three student samples of three countries. 
Table 2. Factor structure of beliefs (Philippines study).

\begin{tabular}{|c|c|}
\hline $\begin{array}{l}\text { Factor } \\
\text { Loading }\end{array}$ & Belief Statement: The Use of Nuclear Energy . . . \\
\hline \multicolumn{2}{|c|}{ Factor I: Negative impacts of large scale technology } \\
\hline 0.87 & .. exposes people to hazards which they cannot influence by any actions of their own \\
\hline 0.78 & . . . involves hazardous agents which cannot be detected by man's senses \\
\hline 0.78 & . . leads to accidents which affect large numbers of people at the same time \\
\hline 0.74 & . . . leads to environmental pollution \\
\hline 0.71 & ... has an impact on people's health \\
\hline 0.71 & . . . leads to dependency on small groups of specialists \\
\hline 0.70 & $\ldots$ is harmful to future generations \\
\hline \multicolumn{2}{|c|}{ Factor II: Progress in national development } \\
\hline 0.84 & .. leads to technological progress \\
\hline 0.81 & . . promotes my nation's industrial development \\
\hline 0.78 & $\ldots$ increases my nation's prestige \\
\hline 0.64 & $\ldots$ prevents brown-outs ${ }^{\mathrm{a}}$ \\
\hline 0.57 & ... stimulates scientific and technological research \\
\hline \multicolumn{2}{|c|}{ Factor III: Fringe benefits } \\
\hline 0.78 & ... provides a cheap energy source \\
\hline 0.67 & $\ldots$ is a long-term solution to energy needs \\
\hline 0.60 & . . leads to a more even distribution of income among nations \\
\hline 0.55 & ... helps to conserve natural resources \\
\hline 0.53 & . . . leads to increased employment \\
\hline
\end{tabular}

a Item only included in Philippine survey.

2. Factor II comprises issues of national interest such as progress and industrial development, prestige, and stimulation of research. It has been termed "Progress in National Development."

3. Factor III seems to represent the more personal benefits that respondents attribute to the use of nuclear energy. Thus the leading items for this factor refer to the economic production of electricity and the capacity to cover the energy needs on a long-term basis. Another aspect of personal concern, the provision of jobs, is also included in this factor, labelled "Fringe Benefits."

In order to determine the influence of the cognitive structure on the attitudinal commitment, a multiple regression analysis was undertaken with the position on nuclear energy as dependent and the factors of the belief systems as independent variables.

For the sample from the Philippines, it can be demonstrated that the best predictor for the attitude is Factor III, ("Fringe Benefits"). This factor is followed by the other benefit-related factor, "Progress in National Development." Factor I ("Negative Impacts of LargeScale Technologies") seems to play only a minor role. Considering the composition of the sample (about $50 \%$ pro- $50 \%$ con, see Fig. 6) it is interesting to note that it is the two benefit factors which seem to be the most indicative aspects for attitude formation of the Philippine sample.

Federal Republic of Germany: Factor analysis of belief scores on nuclear energy of German students yielded four factors, as shown on Table 3. Only one of these factors emphasizes the benefits of nuclear energy, whereas three express concern about the various negative consequences of this energy source.

1. Factor I has been termed "Economic Progress." Items refer to cheap electricity production, improvement of standard of living, and various benefits on a national level.

2. Factor II is similar to Factor I of the Philippine students, since it basically consists of the same items. Thus it received the same labelling, "Negative Impacts of Large-Scale Technologies."

3. Factor III represents a collection of concerns that could develop into a threat, probably not immediately but in the near future. Therefore it is described as "Potential for Threat," including issues such as terrorist activities, passive exposure to hazards, international conflicts, and the long-term danger of radioactive wastes.

4. The possible impact of nuclear power on society is expressed in Factor IV, termed "Restriction of Social Flexibility." Items loading high on this factor refer to the possibility of a unidirectional societal development and the dependency on big industry and their highly specialized professionals.

Computation of multiple regression coefficients as indicators for the attitudinal commitment revealed that, in contrast to the Philippine sample, the perception of "Negative Impacts of Large-Scale Technologies" turned out to be the predominant factor for the formation of attitude. "Economic Progress," the label for Factor I, revealed to be second best predictor. Although the two 
Table 3. Factor Structure of Beliefs (Federal Republic of Germany study).

\begin{tabular}{|c|c|}
\hline $\begin{array}{l}\text { Factor } \\
\text { Loading }\end{array}$ & Belief Statement: The Use of Nuclear Energy . . . \\
\hline \multicolumn{2}{|c|}{ Factor I: Economic progress } \\
\hline 0.75 & ... provides a cheap energy source \\
\hline 0.75 & ... improves our standard of living \\
\hline 0.71 & ... assures the economic independence of my country \\
\hline 0.68 & $\ldots$ promotes my nation's industrial development \\
\hline 0.62 & ... leads to technological progress \\
\hline \multicolumn{2}{|c|}{ Factor II: Negative impacts of larger-scale technology } \\
\hline 0.74 & ... leads to environmental pollution \\
\hline 0.68 & $\ldots$ has an impact on people's health \\
\hline 0.64 & ... leads to accidents which affect large numbers of people at the same time \\
\hline 0.63 & $\ldots$ has a long-term impact on climate \\
\hline 0.60 & $\ldots$ is harmful to future generations \\
\hline \multicolumn{2}{|c|}{ Factor III: Potential for threat } \\
\hline 0.71 & ... provides a source of threats from terrorists \\
\hline 0.59 & . . exposes people to hazards which they cannot influence by any actions of their own \\
\hline 0.44 & ... involves a technology which is usable as a tool in international politics \\
\hline 0.42 & ... postpones the development of alternative energy sources \\
\hline 0.41 & $\ldots$ requires management of dangerous wastes \\
\hline 0.40 & . . . restricts personal freedom through rigorous security measures \\
\hline \multicolumn{2}{|c|}{ Factor IV: Restriction of social flexibility } \\
\hline 0.67 & $\ldots$ leads to consumption-oriented society \\
\hline 0.56 & . . . leads to dependency on small groups of specialists \\
\hline 0.51 & ... restricts options for future societal development \\
\hline 0.47 & ... concentrates power in big industrial enterprises \\
\hline
\end{tabular}

other risk factors, "Potential for Threat" and "Restriction of Social Flexibility" correlate highly with the respondent's position, they do not add any explanatory power to the multiple correlation coefficient.

After interpreting these results, it seems evident that potential threat and social risks as highly complex beliefs do discriminate between different attitudinal positions, but are not the underlying reasons for the initial formation of a position towards nuclear power. Rather, both factors are seen as necessary consequences of the perceived negative impacts of large-scale technologies. Respondents who expected highly negative impacts from the use of nuclear energy were as equally convinced that the threat of political misuse and of social constraints was connected with the general impacts of large-scale technologies.

Japan: The data structure of the Japanese student sample also comprises four factors, again with only one referring to beneficial aspects of nuclear energy but three dealing with threats, hazards and negative impacts (Table 4).

1. Factor I combines the beneficial aspects occupying first place among all factors. It refers to economic advantages such as industrial development, standard of living, and increased employment, and thus it was labelled "Economic Prosperity."

2. Factor II deals with the "Impact of Society" from the use of nuclear energy. Items in this factor include concerns about the national and international power distribution and health considerations.

3. Factor III combines possible impacts on society in the future and has been termed "Long-Term Hazards."

4. Factor IV consists mainly of the same items as Factor III of the German sample. Thus it has been labelled accordingly: "Potential for Threat."

Regarding the relevance of these factors for the attitudinal commitment of this student sample from Japan, "Economic Prosperity" has the highest correlation and therefore takes the first position in the stepwise multiple regression. The third factor, "Long-term Hazards" has the second best predictive power, immediately followed by Factor II, "Impacts on Society." As with the Philippine sample, economic considerations are the best discriminator for different attitudinal positions. Both risk factors, "Impacts on Society" and "Long-term Hazards" are definitely important for the formation of attitudes, but they are by far less decisive than the benefit factor.

Comparative Remarks: As expected, the factor structures derived from the three samples were not identical. Nevertheless, the beliefs about nuclear energy do center around the risks and benefits involved. Thus a comparison between the samples can concentrate on these aspects. While analysis of the beliefs from the German and Japanese students yielded three risk-oriented factors and one benefit factor, Philippine students differentiated between two benefit dimensions, but per- 
Table 4. Factor structure of beliefs (Japan study).

\begin{tabular}{|c|c|}
\hline $\begin{array}{l}\text { Factor } \\
\text { Loading }\end{array}$ & Belief Statement: The Use of Nuclear Energy . . . \\
\hline \multicolumn{2}{|c|}{ Factor I: Impact on society } \\
\hline 0.64 & $\ldots$ concentrates power in big industrial enterprises \\
\hline 0.61 & . . . leads to diffusion of knowledge for construction of weapons \\
\hline 0.58 & ... has an impact on people's health \\
\hline 0.55 & . . . leads to environmental pollution \\
\hline 0.50 & ... involves a technology which is a tool in international politics \\
\hline \multicolumn{2}{|c|}{ Factor II: Economic prosperity } \\
\hline 0.71 & . . . promotes my nation's industrial development \\
\hline 0.70 & . . improves our standard of living \\
\hline 0.69 & . . . leads to technological progress \\
\hline 0.63 & . . . leads to increased employment \\
\hline 0.62 & . . . leads to a more even distribution of income among nations \\
\hline 0.61 & $\ldots$ increases my nation's prestige \\
\hline \multicolumn{2}{|c|}{ Factor III: Long-term hazards } \\
\hline 0.76 & . . . restricts options for future societal development \\
\hline 0.62 & $\ldots$ has a long-term impact on climate \\
\hline 0.61 & $\ldots$ is harmful to future generations \\
\hline \multicolumn{2}{|c|}{ Factor IV: Potential for threat } \\
\hline 0.72 & $\ldots$ requires management of dangerous wastes \\
\hline 0.62 & ... provides a source of threats from terrorists \\
\hline 0.57 & . . . exposes people to hazards which they cannot influence by any actions of their own \\
\hline 0.57 & ... leads to accidents which affect large numbers of people at the same time \\
\hline
\end{tabular}

ceived only one risk dimension. In spite of this general difference in the factor structure, the benefit factor played a major role in all the samples regarding their relative influence on the explanation of the variance of the attitudinal commitment.

\section{Cross-cultural Differences}

In order to detect the main differences between the three samples, discriminant analysis was used. Depending on the parameter that is used for the statistical calculation, all variables were ordered according to the degree to which their variance discriminates between the three samples. Table 5 shows the results obtained with the weighted belief scores of each item (EB-score = beliefs $x$ the evaluations). In the first line, the most discriminative item is listed, followed by the second most discriminative, and so on.

Inspection of Table 5 demonstrates that there are distinct differences with regard to the expected benefits of nuclear energy. The German students emphasize the advantages of cheap energy supply and of conserving natural resources. In contrast, the Philippine students apparently reject these two benefits but are convinced that nuclear energy increases the industrial development of their country and its national prestige. Those two benefits are of no importance for the German students. The Japanese respondents lie in between. Together with the Germans they regard nuclear energy as an inexpensive way of providing electricity, and together with the Philippines they believe in the incentive role of nuclear energy for the development of the national industry. Regard- ing the question of conserving natural resources and increasing national prestige, the Japanese respondents associate both issues with the use of nuclear energy, but not as strongly as the Germans or the Philippines. In contrast to respondents in the German and Philippine samples, the Japanese regard nuclear power as a longterm solution to energy problems.

All three samples react more homogeneously on the risk side, but there are still some distinct patterns that are worth mentioning. The Japanese respondents perceive hardly any risk in connection with radioactive wastes; the Germans show medium concern, whereas the Philippines have a rather negative view on the waste problem. This negative evaluation is also predominant in the question of environmental pollution and-rather unexpectedly -in the restriction of personal freedom.

Most of the results fit into a consistent mosaic composition for each country. The German and Japanese students reflect their industrial heritages by considering nuclear energy as a means of providing inexpensive electricity, encouraging economic progress, and increasing national independence. The Philippine sample perceives nuclear energy as an imported technology with rather doubtful economic advantages and high risks. But they do link nuclear energy with some positive symbolic attributes: increase of prestige as well as encouragement of modernisation and industrial development.

The motivation to "go nuclear" is more functional on the German side, more symbolic on the Philippine side. The Japanese respondents react more like the German students; however, in some aspects concerning national 
Table 5. Discriminant coefficients and mean differences between the three samples with respect to evaluated beliefs.

\begin{tabular}{|c|c|c|c|c|c|}
\hline $\mathrm{EB}^{\mathrm{a}}$ & Lambda $^{b}$ & Sig. ${ }^{c}$ & $\begin{array}{l}\text { Mean for } \\
\text { German } \\
\text { Students }\end{array}$ & $\begin{array}{l}\text { Mean for } \\
\text { Japanese } \\
\text { Students }\end{array}$ & $\begin{array}{l}\text { Mean for } \\
\text { Philippine } \\
\text { Students }\end{array}$ \\
\hline 1. Conserve natural resources (7) & 0.86 & 0.00 & 4.42 & 2.09 & -0.37 \\
\hline 2. Increase nation's prestige (22) & 0.77 & 0.00 & 0.09 & 1.34 & 2.64 \\
\hline 3. Assuring economic independence (12) & 0.69 & 0.00 & 1.92 & 1.33 & -2.16 \\
\hline $\begin{array}{l}\text { 4. Technology as tool in international } \\
\text { politics (15) }\end{array}$ & 0.65 & 0.00 & -1.28 & -1.78 & 0.29 \\
\hline 5. Management of dangerous wastes (6) & 0.60 & 0.00 & -0.08 & 1.73 & -2.71 \\
\hline $\begin{array}{l}\text { 6. Leads to equal income distribution } \\
\text { among nations ( } 30)\end{array}$ & 0.57 & 0.00 & -2.45 & -1.14 & -0.94 \\
\hline 7. Promotes industrial development (3) & 0.54 & 0.00 & 1.93 & 3.14 & 3.58 \\
\hline $\begin{array}{l}\text { 8. Restricts options for future societal } \\
\text { development (21) }\end{array}$ & 0.52 & 0.00 & +2.27 & +0.92 & +0.31 \\
\hline $\begin{array}{l}\text { 9. Postpones the development of alternative } \\
\text { energy sources (14) }\end{array}$ & 0.49 & 0.00 & -0.22 & 2.04 & -1.15 \\
\hline 10. Provides cheap energy (17) & 0.48 & 0.00 & 2.45 & 2.59 & -1.38 \\
\hline 11. Long-term solution to energy needs (19) & 0.48 & 0.00 & 0.35 & 2.21 & -0.13 \\
\hline 12. Restricts personal freedom (2) & 0.46 & 0.00 & 1.90 & 1.30 & -2.16 \\
\hline 13. Leads to environmental pollution (20) & 0.45 & 0.00 & -1.95 & -2.37 & -4.84 \\
\hline 14. Leads to proliferation (28) & 0.44 & 0.00 & -1.46 & -1.35 & -0.89 \\
\hline 15. Uses up valuable land (9) & 0.43 & 0.00 & -1.28 & -1.77 & 0.29 \\
\hline
\end{tabular}

${ }^{a}$ Evaluation times beliefs.

${ }^{\mathrm{b}}$ Correlation coefficient for nominal scaling level.

'Significance of correlation.

prestige and economic development they agree with the Philippine point of view. Functional attitudes are typical for highly industrialized Western cultures; the Japanese are still partly influenced by traditional value systems, but at the same time highly motivated by modern functional evaluations. If the risk aspects had not such a strong impact on the Japanese attitudes, their overall judgement combining functional and symbolic aspects would tend towards a rather well-balanced and stable attitude in favor of nuclear energy.

\section{Conclusion}

This article provided an overview of the theoretical concepts used in the investigation of risk perception, and it presented some empirical results to illustrate the explanatory value of psychological, social-psychological, and sociological research. One main conclusion has already been stated: all the perspectives have their own specific realm of legitimacy, and in combining the various approaches into an overall picture we have the chance to gain a better understanding of risk phenomena.

If we try to separate the risk perception process into steps and to identify the crucial issues which have been proven relevant, we touch the following areas:

1. the significance and expressive power of probabilistic models for intuitive reasoning and risk perception (cognitive heuristics, mechanisms to cope with uncertainty);
2. the question of the degree to which benefits and damage may be collectivized (notion of equity in the distribution of risk and benefits, ethical questions about intergenerational risk shifting);

3. the problem of risk awareness, which seems to be highly influenced by qualitative risk characteristics such as dread, disaster potential, or perceived personal control;

4. the genesis of beliefs about specific risk objects (object-related, situational, and symbolic) and their social determinants;

5. the role of social objectives, values, and power in risk perception (competition for social resources);

6. the significance and credibility of information sources (in particular, scientific expertise); and

7. the form and procedure of the decisionmaking process in risk-related issues (transparency of organizing institutions and public participation).

When looking once again at the most important results of our empirical analyses of risk perception, it becomes evident that these seven areas touch on the focal aspects. On the individual level, the absorption and processing of probabilistic information, the different judgements of disaster potentials, the benefit/ damage distribution effects, as well as personal controllability and familiarity, shape the central patterns in the personal evaluation of risks. In addition, the confidence in the information sources (leading to a selective information acceptance), the decisionmaking mode, as well as social values and attitudes, influence the forma- 
tion and articulation of beliefs concerning the risk object. Risk can also be perceived as a tool for power exchange and can be deliberately associated with interestrelated attributes for the purpose of gaining a superior position in the struggle for social resources (money, prestige, power, influence).

Risk perception is a complex phenomenon that requires more investigations on a multidisciplinary scientific level. For the purpose of risk management it is essential to understand the structure of perception and to recognize the concerns that underlie the overt resistance against modern technologies imposing risks onto the public.

The different motives and incentives for approaching the collective risks taken by civilization with increasing scepticism also do not permit any uniform remedies for solving conflicts regarding risks. For example, when following Zimmerli's recommendations (1981) and answering the question of justifiability in terms of defensive technological ethics (refrain from any action which - due to your judgement of the side-effects - does not permit you to be positive whether you can or cannot afford to risk the side-effects that occur), cautious selection rules for risk-taking would be formulated. For the opponents of large scale technologies, however, such a requirement would be insufficient, and for those who wish more transparency in the political decisionmaking about risks, such a requirement would seem to be too restrictive. Any kind of conflict resolution must face all seven areas simultaneously. This paper is not the place to draw final conclusions for an effective risk management. However, two essential points should be made.

First, the technical calculation of risk dimensions should undoubtedly be regarded as an integral part of any decision on risk sources and, at the same time, be seen as an ideal tool for continuously improving the population's safety. This point, however, is not a controversial issue among the public! To make such calculations the sole criterion of "acceptability" and/or "desirability" of technologies or other civilizational risk sources is in contradiction to the intuitive view of risk acceptance and is also unreasonable from a political and social standpoint.

Second, when reflecting on the abovementioned seven points of risk perception, all models of conflict solution based on technical information work or PR concepts make little sense. What is needed is a qualitative extension of the traditional risk-benefit analysis incorporating not only judgements about technological consequences, but also environmental, social, and political concerns. Thus we can form an analysis of sociotechnological options that can be regarded as alternatives for the envisaged technological and social change. It is of major importance for decisionmaking on risk sources that the implementation of a risk source should be linked with certain social objectives, ideas, and possibly even conceptions of the world which will act as a motor for future policies. Therefore, it is absolutely necessary that the desired and feared effects be regarded not only as quantitative physical changes but also as a reference point within a social context.

\section{References}

Allport, G. W. (1935) "Attitudes", in Handbook of Social Psychology, C. Murchinson, ed., pp. 798-844. Clark University Press, Worcester.

Björk, L. and Hagberg, J. (1983) Probability-knowledge-action. Comments on some recent controversies on applications of probabilistic methods, Stat. Rev. 5, 207-215.

Conrad, J. (1981a) Changing lifestyles: Economic stagnation, postmaterialistic values and the role of the energy debate, in Beyond the Energy Crisis-Opportunity and Challenge, R. A. Fazzolare and C. B. Smith, eds. vol. 4, pp. 2127-2134. Pergamon Press, Oxford.

Conrad, J. (1981b) Society and problem-oriented research: On the socio-political functions of risk assessment, in Risk: A Seminar Series, H. Kunreuther, ed. pp. 87-110. IIASA Collaborative Proceedings Series, CP-82-S2, International Institute for Applied Systems Analysis, Laxenburg, Austria.

Covello, V. T. (1983) The perception review. Report of the National Science Foundation, Washington, DC.

Covello, V. T., Menkes, J., and Nehnevasja, J. (1982) Risk analysis, philosophy, and the social and behavioural sciences, reflections on the scope of risk analysis research, Risk Anal. 2, 53-58.

De Finetti, A. (1974) Theory of Probability: $A$ Critical Introductory Treatment. Wiley, New York, NY.

Del Sesto, S. L. (1979) Science, Politics, and Controversy: Civilian Nuclear Power in the United States, 1946-1974, Westview Press, Boulder, $\mathrm{CO}$

Douglas, M. and Wildavsky, A. (1982) Risk and Culture. University of California Press, Berkeley, CA.

von Erichsen, L.V. (1962) Die friedliche Nutzung der Kernenergie, Ihre Vorteile und Gefahren. Springer Verlag, Berlin, Göttingen, Heidelberg.

Fischhoff, B., Slovic, P., Lichtenstein, S., Read, S., and Combs, B. (1978) How safe is safe enough? A psychometric study of attitudes toward technological risks and benefits, Policy Sci. 9, 127-152.

Fischhoff, B., Slovic, P., and Lichtenstein, S. (1981) "The Public" vs. "The Experts": Perceived vs. actual disagreements about risks, in Risk: A Seminar Series, H. Kunreuther, ed., pp. 171-193. IIASA Collaborative Proceedings Series, CP-82-S2, International Institute for Applied Systems Analysis, Laxenburg, Austria.

Fishbein, M. (1963) An investigation of the relationship between beliefs about an object and the attitude toward that object, $\mathrm{Hu}$ man Relat. 16, 233-240.

Fishbein, M. and Ajzen, J. (1975) Belief, Attitude, Intention and Behaviour. An Introduction to Theory and Research. Addison Wesley Com., Reading, MA

Frederichs, G., Bechmann, G., and Gloede, F. (1983) Großtechnologien in der gesellschaftlichen Kontroverse. KFK-Report-3342, Kernforschungszentrum Karlsruhe, Karlsruhe.

German Reactor Safety Commission (Gesellschaft für Reaktorsicherheit) (1979) Die deutsche Risikostudie. Kurzfassung, TÜVVerlag, Köln, Bonn.

Glennon, D.P. (1980) A study of measuring the "acceptable risk" of technology with particular references to perceived risks from a nuclear power plant in western Australia. Self-published report, Sydney.

Hammond, K. R., McClelland, G. H., and Mumpower, J. (1978) Human judgment and decision making. Preager Special Studies, Hemisphere Publishing, Boulder, CO.

Hoos, I. (1980) Risk assessment in social perspective, in Perception of Risk, National Council on Radiation Protection and Measurement, pp. 57-84. Washington, DC.

Janis, I. L. and Mann, L. (1977) Decision Making. The Free Press, New York, NY.

Jungermann, H. (1983) The two rationality camps, in Decision Making under Uncertainty, R. W. Schwartz, ed. North Holland Publishing, New York, NY. 
Jungermann, H., von Winterfeldt, D., and Coppock, R. (1982) Analysis of acceptability of hazardous technologies and their risks. Workshop Report, IIES-dp-82-2, International Institute for Environment and Society, Wissenschaftszentrum Berlin, Berlin.

Keeney, R. L. and Raiffa, H. (1976) Decision with Multiple $O b$ jectives: Preferences and Value Tradeoffs. Wiley, New York, NY.

Keeney, R. L. (1980) Equity and public risk, Operations Res. 28, $527-534$.

Kitschelt, H. (1980) Kernenergiepolitik-Arena eines gesellschaftlichen Konfliktes. Campus, Frankfurt, New York.

Klineberg, O. (1954) Social Psychology. Wiley, New York, NY.

Kluckhorn, C. (1951) Values and value orientations in the theory of action in Toward a General Theory of Action, T. Parsons and E. Shils, eds., pp. 388-433. Harvard University Press, Cambridge, MA

Lichtenstein, S., Slovic, P., Fischhoff, B., Laymann, M., and Combs, B. (1978) Judged frequency of lethal events, Exper. Psychol.: Human Learning and Memory 4, 551-578.

Lopes, L. L. (1983) Some thoughts on the psychological concept of risk, Exper. Psychol.: Human Perception and Performance, 1, 137-144.

Mazur, A. (1975) Opposition of technological innovation, Minerva $13,58-81$

National Council on Radiation Protection and Measurement (1980) Perceptions of Risk, Proceedings of the 15th Annual Meeting, March 14-15, 1979, Washington, DC.

National Research Council (1983) Risk Assessment in the Federal Government: Managing the Process. National Acadamy Press, Washington, DC.

Nelkin, D. (1977a) Technological Decisions and Democracy. Sage Publications, Beverly Hills, CA.

Nelkin, D. (1977b) Controversies and the Politics of Equal Time. MIT Press, Cambridge, MA.

Nowotny, H. (1976) Social aspects of the nuclear power controversy. IIASA Report Memorandum, RM-76-33, International Institute for Applied Systems Analysis, Laxenburg, Austria.

Okrent, D. and Whipple, C. (1977) Approach to societal risk acceptance criteria and risk management. UCLA-ENG-7746, University of California, Los Angeles, CA.

Otway, H. J. (1977) A review of research on the identification of factors influencing the social response to technological risks. IAEA - Proceedings of the International Conference on Nuclear Power and its Fuel Cycle, CN-36-4, International Atomic Energy Agency, Vienna.

Otway, H. J. (1980) Perception and acceptance of environmental risk, Z. Umweltpolitik 2, 593-616.

Otway, H. J. and von Winterfeldt, D. (1982) Beyond acceptable risk: On the social acceptability of technologies, Policy Sci. 14, 247-256

Pages, J. P., Morlat, G., and Stemmelen, E. (1982) Structures de l'opinion publique et débat nucléaire dans la société francaise temporaine, Revue Générale Nucléaire 2, 140-149.

Perrow, C. (1984) Normal Accidents. Living with High-Risk Technologies. Harvard University Press, Cambridge, MA.

Rammstedt, O. (1981) Was heißt soziologisch Risiko?. Presented at the Workshop: Analysis, Evaluation and Acceptability of Hazardous Technologies and their Risks, Dec. 14-15, Berlin.

Renn, O. (1980) Die sanfte Revolution-Zukunft ohne Zwang? Girardet, Essen.

Renn, O. (1981) Man, technology and risk. KFA-Special Report, Jül-Spez-115, Nuclear Research Centre, Jülich.

Renn, O. (1982) Nuclear energy and the public: Risk perception, attitudes, and behaviour. Proceedings of the Third Conference of the Uranium Institute, "Uranium and Nuclear Energy," London, Sept. 2-4, 1981, pp. 242-258. Butterworth Scientific Limited, London.

Renn, O. (1983) Technology, risk and public perception, Appl. Systems Anal., 4, 50-65.

Renn, O. (1984) Risikowahrnehmung der Kernenergie Campus, Frankfurt, New York.

Renn, O. and Peters, H. P. (1982) Intuitive risk perception: Research results of attitude surveys toward risk and technology. Proceedings of the International ANS/ENS Topical Meeting on Probabilistic Risk Assessment, Portchester, Sept. 20-24, 1981, pp. 1464-80.
American Nuclear Society, New York, NY.

Rokeach, M. (1968) The nature of attitudes, in International Encyclopaedia of the Social Sciences, D. L. Sills, ed., vol. 1, pp. 449458. New York, NY.

von Rosenstiel, L. and Ewald, G. (1981) Marktpsychologie, Bd. 1, Konsumverhalten und Kaufentscheid, pp. 92-102. Kohlhammer, Stuttgart, Berlin, Köln, Mainz.

Ross, L. (1977) The intuitive psychologist and his shortcomings, in Advances in Social Psychology, L. Berkowitz, ed. Academic Press, New York, NY.

Royal Society (1983) Risk assessment. A study group report. The Royal Society, London.

Schäfer, R. E. (1978) What are we talking about when we talk about risk? A critical survey of risk and risk preference theories. IIASA research memorandum, RM-78-69, International Institute for Applied Systems Analysis, Laxenburg, Austria.

Slovic, P., Fishhoff, B., and Lichtenstein, S. (1979) Rating the risk, Environ. 21, 14-39.

Slovic, P., Fischhoff, B., and Lichtenstein, S. (1980) Facts and fears: Understanding perceived risk, in Societal Risk Assessment: How Safe is Safe Enough?, R. Schwing and W. Albers, eds., pp. 181-216. Plenum Press, New York, NY.

Slovic, P., Fischhoff, B., and Lichtenstein, S. (1981a) Characterizing Perceived Risk in Technological Hazard Management, R. W. Kates and C. Hohenemser, eds. Oelschlager, Gum \& Hain, Cambridge, MA.

Slovic, P., Fischhoff, B., and Lichtenstein, S. (1981b) Perceived risk: Psychological factors and social implications", in The Assessment and Perception of Risk, Series A 376, pp. 17-34. The Royal Society, London.

Slovic, P. and Fischhoff, B. (1984) "How safe is safe enough? Determinants of perceived and acceptable risk", in Too Hot to Handle: Social and Policy Issues in the Management of Radioactive Wastes, L. Gould and C. A. Wales, eds., in press. Yale University Press, New Haven, CT

Starr, C. (1969) Social benefit versus technological risk, Science 165 , $1232-1238$.

Swaton, E. and Renn, O. (1984) Attitudes towards nuclear power, a comparison between three nations. IIASA working paper WP-84-11, International Institute for Applied Systems Analysis, Laxenburg, Austria.

Thomas, K., Maurer, D., Fishbein, M., Otway H., Hinkle, R., and Simpson, D. (1980) A comparative study of public beliefs about five energy systems. IIASA research report RR-80-15, International Institute for Applied Systems Analysis, Laxenburg, Austria.

Thomas, K. (1981) Comparative risk perception: How the public perceives the risks and benefits of energy systems. in The Assessment and the Perception of Risk, Series A 376, pp. 35-50. The Royal Society, London.

Thompson, M. (1980) An outline of the cultural theory of risk. IIASA Working paper WP-80-177, International Institute for Applied Systems Analysis, Laxenburg, Austria.

Tubiana, M. (1979) One approach of the study of public acceptance, in Directions in Energy Policy. A Comprehensive Approach to Energy Resource Decision-Making, B. Kursunoglu and A. Perlmutter, eds., pp. 343-356. Ballinger, Cambridge, MA.

Tversky, A. and Kahnemann, D. (1974) Judgment under uncertainty: heuristics and biases, Science 185, 1124-1131.

Tversky, A. and Kahnemann, D. (1981) The framing of decision and the psychology of choice, Science 211, 453-458.

Wildavsky, A. (1980) Richer is safer, Public Interest 60, 23-29.

von Winterfeldt, D., John, R. S., and Borcherding, K. (1981) Cognitive components of risk taking. Social Science Research Institute (University of Southern California, Los Angeles, CA), Sonderforschungsbereich Entscheidungstheorie an der Universität Mannheim.

Wünschmann, A. (1984) Unbewußt dagegen. Zur Psychologie der Kernenergie-Kontroverse, Bonn aktuell, 3rd ed., Stuttgart.

Zimmerli, W. Ch. (1981) Gesellschaftliches System und Wandel ethischer Normenbegründung. Grenzen der systemtheoretischen Betrachtungsweise bei der aktuellen Suche nach einer Ethik der Technik, in Technikfolgen und sozialer Wandel, J. von Krudener and J. von Schubert, eds. Verlag Wissenschaft und Politik, Köln. 